\title{
En marxistisk tolkning av Estland efter kommunismen
}

\author{
Risto Alapuro
}

SAMMANDRAG: I sin utförliga recension av Peter Bötkers avhandling Leviatan $i$ arkipelagen. Staten, förvaltningen och sambället. Fallet Estland (Stockholms universitet 2007) får Risto Alapuro tillfälle att diskutera Estlands postsovjetiska samtidshistoria. Där samhällsvetenskapliga analyser av de postkommunistiska samhällena vanligtvis delar en "konstruktiv" utgångspunkt med fokus på övergången till marknadsekonomi och demokrati, avviker Bötkers kritiska marxistiska perspektiv. I fokus för Leviatan i arkipelagen står istället analysen av de politiska och ekonomiska maktstriderna mellan fraktioner inom den dominerande klassen efter självständigheten. Denna kamp om resurser utspelar sig i ett samhälle som avhandlingen beskriver som en "fragmenterad arkipelag", ett postmodernt socialt landskap med svag regeringsmakt, svag statsförvaltning och svagt civilt samhälle. I sin kritiska genomgång välkomnar Alapuro den provokativa ansatsen samtidigt som han lyfter fram relevant forskning som Bötker underlåter att diskutera och kritiserar den ofta osystematiska och oreflekterade användningen av empirin.

NYCKELORD: Estland; postkommunism; postmodernitet; marxism; klassteori; statsförvaltning; massorganisationer.

PUBLICERINGSHISTORIK: Originalpublicering. En till engelska översatt version av den här artikeln har tidigare publicerats som "A Marxist interpretation of post-Communist Estonia”, i Baltic Worlds, volym I, nr I 2008.

RISTO ALAPURO är professor emeritus i sociologi, senast vid Helsingfors universitet I99I2010.

E-POSTADRESS: risto.alapuro@helsinki.fi

FÖRSLAG PÅ KÄLLANGIVELSE:

Alapuro, Risto (2013) "En marxistisk tolkning av Estland efter kommunismen”, i Arkiv. Tidskrift för sambällsanalys, nr I, s. 87-96. DoI: http://dx.doi.org/IO.I3068/2000-62I7.I.4

(C) Risto Alapuro/Arkiv förlag \& tidskrift 20I3 (publicerad 2 december 20I3)

Artikeln distribueras enligt en upphovsrättslicens från Creative Commons: Erkännande-Ickekommersiell-IngaBearbetningar 3.0 Unported, som medger fri ickekommersiell användning och spridning i oförändrat skick så länge källan anges. 
Arkiv. Tidskrift för samhällsanalys är en sakkunniggranskad vetenskaplig tidskrift för samhällsvetenskap och historia. Samtliga artiklar publiceras fritt tillgängliga på:

www.tidskriftenarkiv.se

(beständig länk, DoI: http://dx.doi.org/IO.I3068/2000-62I7)

Den här artikeln finns tillgänglig i följande format:

PDF \& HTML: via beständig länk, DOI: http://dx.doi.org/IO.I3068/2000-62I7.I.4 EPUB: ingår i e-boksutgåva av numret, ISBN: 978 9I 79242503

TRYCK: ingår i bokutgåva av numret, ISBN: 978 9I 7924 25I O

Grafisk utformning och sidnumrering är identisk i pdf och tryck.

Samtliga artiklar i nr I (2013) nås via beständig länk, DOI: http://dx.doi.org/I0.13068/2000-6217.I

Arkiv. Tidskrift för sambällsanalys ISSN: 2000-62I7 (för elektronisk resurs)

ISSN: 2000-6225 (för tryckta nummer)

ges ut av

Stiftelsen Arkiv för främjande och spridning av samhällsvetenskaplig och historisk forskning

genom

Arkiv förlag \& tidskrift

Box 1559

SE-22I OI Lund

BESÖK: L Gråbrödersg $3 \mathrm{c}$, ipg

TEL: O46-I3 3920

ARKIV FÖRLAG: arkiv@arkiv.nu·www.arkiv.nu

TIDSKRIFTEN ARKIV: red@tidskriftenarkiv.se · www.tidskriftenarkiv.se

ANSVARIg UTGIVARE \& CHEFREDAKTÖR: Sven Hort

ADMINistrativ RedAKTÖr: David Lindberg

RedAKtörer: Paavo Bergman, Lisa Kings, Zhanna Kravchenko 


\title{
En marxistisk tolkning av Estland efter kommunismen
}

\author{
RISTO ALAPURO
}

\section{I}

Samhällsvetenskapliga analyser av utvecklingen i de postkommunistiska länderna i Östeuropa och östra Centraleuropa bygger för det mesta på olika sätt att se på den mer eller mindre smärtsamma uppkomsten eller återkomsten av marknadsekonomin, civilsamhället och den demokratiska staten. Analyserna kan inbegripa kritik men har vanligtvis en "konstruktiv" utgångspunkt, som visar sig i de dominerande teoretiska grepp som används: olika teorier om statsbildning, (post)modernisering, övergången till demokrati med mera.

Peter Bötkers avhandling Leviatan i arkipelagen. Staten, förvaltningen och sambället. Fallet Estland (Stockholms universitet, 2007) ${ }^{\mathrm{I}}$ avviker från detta mönster; boken är tydligt oppositionell. Bötker betraktar Estlands utveckling under de senaste $15-20$ åren ur marxistiskt perspektiv och tar i den traditionen avstamp i den franska 1960- och 1970-talsteoretikern Nicos Poulantzas och hans statsteori. Enligt Poulantzas avgörs tillhörigheten till den dominerande klassen av kontrollen över produktionsmedlen, och staten är den arena där klasserna och klassfraktionerna kämpar om dominans och reglering. Staten är "en organisationsfaktor för den

I. Beständig länk: http://urn.kb.se/resolve?urn=urn:nbn:se:su:diva-6756.

En till engelska översatt version av den här artikeln har tidigare publicerats som "A Marxist interpretation of post-Communist Estonia", i Baltic Worlds, volym I, nr I 2008. 
dominerande klassen”, som Bötker konstaterar. I linje med detta är det först och främst politiska partier som utgör "den dominerande klassens representanter och agenter" i staten (s. 35-36).

Bötker tecknar en mycket kritisk bild av kopplingarna mellan staten, ekonomin och civilsamhället och riktar särskilt in sig på förhållandet mellan den estniska statsförvaltningen och regeringsmakten. Han menar att både förvaltningen och regeringsmakten har varit svaga i Estland, i motsats till den teoretiskt grundade och förståeliga idén att regeringen eller den politiska makten är stark när byråkratin eller den verkställande makten är underordnad politikernas makt - med andra ord när byråkratin är svag - eller den lika förståeliga idén att regeringen eller den politiska makten är svag när de som verkställer regeringens politik har stor handlingsfrihet - med andra ord när byråkratin är stark.

Bötker försöker alltså beskriva och förklara de faktorer som har medfört att svaga regeringar i Estland har åtföljts av svag förvaltning. Denna hypotes ligger till grund för studien, men är i själva verket snarare en ganska lös utgångspunkt för en mer allmän diskussion om förhållandet mellan staten och samhället än en fast riktlinje för analysen.

Enligt Bötker var det avgörande i Estlands frigörelse från Sovjet att delar av Sovjetestlands styrande klass å ena sidan förlorade kontakten med samhället - "de centrifugala krafterna mellan 1987 och 1992 kastade staten och aktörerna i det sociala landskapet åt olika håll” (s. 244) - och å andra sidan började konkurrera om den statliga egendom som senare kom att privatiseras. Samtidigt som striden om egendomsfördelning rasade under privatiseringen blev Estland snabbt ett "kapitalintensivt" land, med växande kapitalvolymer, ökad kapitaltillgänglighet och intensiva kapitalrörelser mellan olika aktörer. Det gynnade dem som kunde etablera sig i staten - den dominerande klassens olika fraktioner och de som lyckades få en plats i "hovet", nära statens mest centrala aktörer.

Denna utveckling medförde att de statsbärande organisationerna inte behövde massunderstöd - som Bötker säger "underminerar [kapitalintensiteten] skapandet av en djup och bred inbäddning av de politiska partierna i det sociala landskapet" (s. 133). Resonemanget bygger på Apostolis Papakostas analys av förändringen i massrörelsers och massorganisationers karaktär - på idén om ett tillstånd som Bötker kallar postmodernt. 
En aspekt av situationen är att organisationerna i allmänhet inte längre behöver massorna. "[N]är industrisamhällets organisationer baserades på mångas få resurser [och massmedlemskap var viktigt] så har istället organisationerna, under senare tid, hittat kortare vägar till [...] resurser.” Kapitalintensiteten har öppnat nya vägar för att finansiera verksamheten. Medlemmarna har omvandlat sig "till sympatisörer, eller till konsumenter av organisationens verksamhet" (s. 79-80).

Kapitalintensiteten leder inte bara till att medlemsbaserade massorganisationer blir onödiga för organisationer och för de dominerande aktörer som utnyttjar dem. Den innebär också att människor själva vänder organisationerna ryggen. Deras sätt att organisera sig har fragmenterats. I det postmoderna tillståndet "uppstår en arkipelag av små apolitiska, privata och individualiserade områden" (s. 247), ett tillstånd som enligt Bötker är synligt i Estland. Länken mellan medborgarna och staten är svag. De politiska partierna är inte förankrade i grupper i det civila samhället, massammanslutningarna har få medlemmar, röstandet är mycket instabilt och varierar från ett val till ett annat, och så vidare. Denna tendens angår inte enbart de postkommunistiska länderna utan också, som vi vet, de "gamla" demokratierna. Organisationer fragmentariseras och upplevelser individualiseras såväl i Västeuropa som i Estland, hävdar Bötker.

Privatiseringen av statens egendom inverkar på relationerna mellan den dominerande klassens fraktioner och tar sig uttryck i partistrider. Privatiseringen har slagit in kilar mellan fraktioner, och det är här man måste söka förklaringen till de estniska regeringarnas inre svaghet på I990- och 2000-talen, menar Bötker: "de estniska regeringarna har splittrats inifrån, på grund av [kapitalintensitet]" (s. I34-I35).

Den främsta skiljelinjen mellan olika fraktioner tycks vara linjen mellan dem som Bötker vanligen kallar "de före detta" (eller ibland "de gamla") och "de nya", och följaktligen mellan och inom regeringar som har representerat än de förra, än de senare, med varierande inställning till privatiseringen och dess förverkligande. Båda grupperna saknar "breda och djupa kontaktytor i det civila samhället". "De före detta” bestod "bland annat av de aktörer som under den gamla regimens tid befann sig i sådana positioner som tillät dem att kontrollera produktionsmedlen", och "de nya" av "aktörer som tidigare stod utanför den dominerande 
klassen [men som] kunde tåga in på statsarenan” (s. I34-I35). I olika sammanhang ger han exempel på personförbindelser mellan partier och den ekonomiska eliten. Bland regeringarna som har dominerats av "de nya" intar Mart Laars första regering 1992-1994 en särställning, eftersom "de nya” då för första gången hade regeringsmakten - en situation som ökade kapitalintensiteten och blottlade spänningar mellan den dominerande klassens fraktioner.

Bötker förklarar aldrig termerna "de före detta" och "de nya", som tydligen kommer från den offentliga debatten i Estland. Det hade varit belysande att analysera dem, istället för att ta dem för givna.

De omfattande privatiseringarna var avgörande för kapitalintensitetens tillväxt. "[E]fter statens reträtt [uppstod möjligheter] att tillskansa sig resurser." Kapitalintensiteten "medförde att ett antal motstridiga men oberoende fraktioner inom den dominerande klassen uppstod" (s. 134). Vilka är dessa fraktioner? Bötker preciserar dem inte men citerar en journalist som i början av 1990-talet ansåg att det "utöver de statliga företagens direktörer [fanns] två tongivande klassfraktioner [vilkas] intressen stod bakom de flesta ekonomiska och politiska strider”. Den första var Estlands motsvarighet till Skattebetalarnas förening, som bestod av personer med anknytning till "Riksbanken, Hansabanken, Tartu Krediitbank, Hoiubanken och storföretaget Eesti Talleks". Den andra fraktionen bestod av "det kapital som framförallt arbetade med transithandel” (s. I5I).

Många problem i den estniska statsförvaltningen har anknytning till kapitalintensiteten. Kapitalintensiteten och de sprickor den har skapat mellan den dominerande klassens fraktioner är "en orsak till att den estniska statsförvaltningen varken har kunnat hävda sina expertpositioner eller bygga allianser med aktörer i det sociala landskapet” (s. I33). Sprickorna ledde till "att olika partier kunde sätta statsförvaltningens olika enheter på en kollisionskurs" (s. 24I). Statsförvaltningen har varit offer för varierande krav och förväntningar under olika regeringar, och för den privata sektorns konkurrens om kompetenta tjänstemän. Samtidigt saknas alliansbyggande med aktörer i det civila samhället - som i en viss form existerade under sovjettiden och som kunde ha gjort förvaltningen starkare och ökat dess manöverutrymme. 
I boken finns det ändå ingen systematisk analys av svaghetsproblemet. Bötker betonar också här den roll 1992 års koalition spelade, när "de nya” för första gången hade regeringsmakten. De förändringar koalitionen satte i verket var riktade mot den gamla byråkratin: "de radikala omstruktureringar av statsapparaten som regeringskoalitionen [...] vidtog [...] 1992 måste ses i ljuset av detta hot om att den gamla byråkratin kan ta över" (s. I89). Nästa gång "de nya" satt i regeringen under Mart Laars ledning, i slutet av 1990-talet, var också en tid av förändringar, men denna gång handlade det inte så mycket om omstruktureringar som om personalomsättningen. Under hela 1990-talet var statsförvaltningen underkastad olika strukturförändringar, och omplaceringar var vanliga också under "de före dettas" regeringar. Det fanns inte mycket tid för en ömsesidig inlärningsprocess, och "kansliet" kom ofta i kläm när förväntningarna snabbt växlade. Regler har förändrats många gånger, beslutanderätten har koncentrerats på olika nivåer under olika regeringar, bekantskap har spelat stor roll i rekryteringen, och så vidare. Allt detta har stört institutionaliseringsprocessen.

Bötker citerar siffror som visar att personalomplaceringen i olika ministerier var omfattande och ledde till osäkerhet och andra problem bland tjänstemännen. Förutom talrika regeringsskiften som ledde till personalförändringar nämner han generationsbytet, atmosfären och personliga spänningar i förvaltningen och andra sektorers konkurrens angående speciellt unga tjänstemän. Det är i ljuset av denna dubbla utveckling kortvariga och konfliktfyllda regeringar och en icke-institutionaliserad byråkrati - som man kan förstå att en svag regering inte implicerar en stark förvaltning, som den borde enligt teorin. I Estland samexisterar svaga regeringar med en svag förvaltning.

Allt sammantaget tecknar Bötker en bild av att sovjettidens styrande klass, tack vare sin ställning i staten, kunde erövra ekonomiska och politiska resurser i övergången till självständighet. De koncentrerade sig på staten och den nya kapitalintensiva ekonomin, och de vände sig bort från civilsamhället, som de inte behövde längre. I sin strävan fick "de före detta" sällskap av nykomlingar i den ekonomiska eliten, med vilka de utkämpade en strid om ekonomisk och politisk makt - en strid vars konturer går att urskilja i Estlands växlande regeringskoalitioner. Bötkers 
logik påminner om beskrivningar av hur den ryska eliten omformades under Jeltsins vilda privatiseringsår i början av I990-talet.

\section{II}

Det går inte att förneka att Bötkers provokativa resonemang äger en viss intuitiv rimlighet. Det visar oss ett annat sätt att se på den så kallade övergången - som en version av kombinationen av kapitalistisk modernisering och postmodern social utveckling i allmänhet - under en tid av djupgående förändringar. Fokuseringen på staten, ekonomin och deras inbördes förhållande, och på hur grupper som är förankrade i staten kan dra nytta av perioder när allt tycks vara i rörelse och möjligheter plötsligt öppnar sig, verkar lämplig för en realistisk analys av postsocialistiska stater. Detta angreppssätt har dock inte varit vanligt i samhällsvetenskapliga analyser av Estlands omvandling. Enkelt uttryckt riktar fokuseringen på staten vår uppmärksamhet mot maktpositioner och mot de resursstrider som makthavare och deras koalitioner utkämpar, medan den gängse fokuseringen på nationsbyggandet och civilsamhället riktar uppmärksamheten mot integration, gemensamma värderingar och andra kulturella faktorer respektive mot föreningslivets (åter)födelse.

Bötkers perspektiv är ett välkommet brott mot de brukliga tendenserna i forskningen om Estland efter kommunismen. Men det berättigar inte att han underlåter att sätta sitt synsätt och sina resultat i relation till andra forskares synsätt och resultat; man förväntar sig en diskussion med dem för att kunna avgöra hur övertygande Bötkers argument är.

Ett annat, ännu viktigare, bedömningskriterium är styrkan eller svagheten hos hans empiri. Det originalmaterial som Bötker själv har samlat in består av intervjuer med tjugo estniska tjänstemän: sju på ekonomiministeriet, sju på finansministeriet och sex på rikskansliet. Avsikten var att låta "nuvarande och före detta tjänstemän presentera sin version av förvaltningens position i estniskt politikskapande och hur organisationen i estniska ministerier, enligt dem, fungerade och fungerar" (s. 40). Intervjufrågorna gällde centrala teman i avhandlingen, och de kodades systematiskt för att ge besked om bland annat strukturförändringar, prioritetsförändringar, chefsbyten och rivalitet mellan ministeriernas 
olika enheter. Utöver intervjuer och samtal med politiker och tjänstemän utnyttjade Bötker dagspressen och naturligtvis många vetenskapliga publikationer, i synnerhet estniska och estniskspråkiga.

Bötkers data verkar vara intressanta, att döma av många brottstycken i bokens olika kapitel, men deras värde för analysen minskar på grund av att de används osystematiskt och oreflekterat. Information från intervjuerna kombineras ofta med uppgifter ur dagspressen eller från annan forskning, utan hänsyn till källornas olika art - och vad värre är framgår det inte alltid om de intervjuade bör ses som informanter som förmedlar fakta eller som studieobjekt vilkas uttalanden kan färgas av tjänstemännens subjektiva uppfattningar om styrkeförhållandet mellan dem och de politiska ledarna.

Den vaga användningen av empirin är ett mer allmänt problem. I många fall har författarens reflektioner bara lös anknytning till den empiriska informationen. Bötker lägger fram resonemang som flyter fritt utan att begränsas av eller prövas mot empiriska belägg. Allt detta minskar förstås resultatets informationsvärde, även om reflektionerna själva ofta är intressanta.

Problemet är också uppenbart i bristen på diskussion med annorlunda eller till och med motsägande resultat och tolkningar från andra forskare, däribland många estniska sociologer och statsvetare. Bötker kritiserar deras arbete mer implicit än explicit, och utan att ge sig in i en allvarligt menad diskussion. Bra exempel är uppdelningen av den styrande klassen i "de före detta" och "de nya" och den låga organiseringsnivån i de länder som har upplevt övergången från kommunism. Det här är viktiga frågor med inverkan på framväxten av en postkommunistisk elit och på civilsamhället och dess organisationer - inte bara i början av I990-talet utan även senare. Rein Ruutsoo, en av dem som utförligt har analyserat både elitens formering och den folkliga organiseringen från "den sjungande revolutionen" och framåt, beskriver att eliten till en början var uppdelad i folkfronten och kongressen och knyter därigenom "de nya” i Bötkers analys, särskilt Pro Patria och Mart Laar, till den senare, radikalt nationalistiska, linjen. Det hade varit intressant och troligen mycket informativt att läsa om förhållandet mellan denna ideologiskpolitiska gränsdragning och den ekonomisk-politiska mellan "de före 
detta" och "de nya”. Ruutsoo reflekterar också över förändringen från "rörlighetssamhället" vid decennieskiftet 1990 till den nedgång i organiseringsprocessen som präglade 1990-talet, och han betonar på många sätt de speciella omständigheter som rådde i Estland under övergångsperioden. Men Bötker bortser från alla förklaringar som har med övergången från kommunism att göra genom att helt enkelt hänvisa till den tillbakagång för massorganisationer som postmodernismen för med sig: "den postmoderna fragmenteringen av samhället ser ut att ha andra och mycket djupare rötter i vissa samhällen än ett övergivande av ett visst samhällstillstånd" (s. 72).

Både elitens uppdelning och föreningslivets karaktär är viktiga ämnen som Bötker betraktar på ett högst originellt sätt, och en explicit jämförelse med andra tolkningar hade kunnat stärka trovärdigheten hos hans analys.

Avhandlingens viktigaste iakttagelse - att Estland har både en svag regering och en svag förvaltning - kan också förklaras med hänvisning till övergångsproblemet. Det tycks mig att Bötker, utan att erkänna det, åberopar orsaker till denna dubbla svaghet som har med övergången eller omvandlingen att göra: omstruktureringar, omplaceringar, affärslivets konkurrens om kompetenta tjänstemän och så vidare. Därför framstår den gåta som Bötker lägger fram som avhandlingens utgångspunkt något konstlad. Men som jag skrev ovan är denna iakttagelse faktiskt snarare en utgångspunkt för att undersöka Estlands stat och samhälle i allmänhet än det är en strikt hypotes som har väglett studien.

Ett annat slående exempel på hur Bötker undviker samröre med tidigare forskning är hur han behandlar 200o-talets utvidgning av de folkliga organisationerna. Han nämner visserligen att medborgarorganisationerna blev fler och fick fler medlemmar mellan slutet av i990-talet och 2005, som estniska forskare har visat. "Medborgarna i Estland tycks [...] vara mycket aktiva med att organisera sig" (s. 126). Men han förkastar denna tolkning och påpekar bland annat att de flesta organisationerna är små, att nya medlemmar huvudsakligen värvas ur befintliga medlemmars bekantskapskretsar samt att sport- och kulturföreningar dominerar. Detta sistnämnda faktum stöder, enligt Bötker, uppfattningen att politiskt relevanta sammanslutningar har en undanskymd plats, och han fin- 
ner fog för sitt argument: "När det civila samhället lever sitt eget aktiva liv, där människor sköter allt annat än att delta i de statsbärande organisationerna, uppstår trots ett vitalt civilt samhälle ett avstånd mellan stat och medborgare" (s. I27). Men detta är bara ett resonemang in abstracto, ett val av sida i debatten om vilken roll opolitiska organisationer spelar i den demokratiska utvecklingen, inte mer. Problemet förvärras av att det faktiskt finns estniska studier och motsatta bedömningar (av bland andra Mikko Lagerspetz och Erle Rikmann) av vad de senaste årens skeende har betytt. Det är också slående att Bötker inte vill bedöma Plan för utvecklingen av det estniska civilsambället (Eesti Kodanikeühiskonna Arengu Kontseptsiooni, EKAK), det ramdokument för att reglera förhållandet mellan föreningarna och staten som Estlands parlament antog 2002. Han nämner det inte ens, trots att det finns forskning som hävdar att det är viktigt, och trots att han i förbigående konstaterar att ministerierna samarbetar mer med medborgarsammanslutningarna nu än på I990-talet och att det till och med finns idéer om att låta dem ta över en del offentliga funktioner.

Den rysktalande befolkningen lyser med sin frånvaro i avhandlingen, vilket jag tycker är anmärkningsvärt i en studie som behandlar den estniska staten och förhållandet mellan staten och samhället ur den förras perspektiv. Även om det är sant att en betydande andel av de 30 procent av befolkningen som inte är etniska ester inte är medlemmar i staten (alltså medborgare) är de ändå medlemmar i samhället och bidrar därmed till att forma förhållandet mellan staten och samhället. Situationen speglar att Estland är en "nationaliserande stat", vilket är en viktig del av interaktionen mellan staten och samhället. Men jag medger att beslutet att bortse från de rysktalande ligger i linje med Bötkers ekonomiskpolitiska statsbegrepp.

\section{III}

Oaktat den kritik jag har riktat mot Bötkers avhandling kvarstår dess största förtjänst, nämligen det omoderna och till och med provokativa försöket att i en analys av det nya Estland rikta fokus mot "hårda" ekonomiska och politiska maktstrider samt rivalitet om resurser. Närmare 
bestämt: i sin undersökning av förhållandet mellan den politiska ledningen och förvaltningen i en "ny demokrati" valde Bötker ett aktuellt och föga studerat ämne. Valet vittnar om hans beslutsamhet att granska en socialt och politiskt central övergripande fråga i en doktorsavhandling. Ämnet är besvärligt att arbeta med - vilket förklarar en del av de problem han mötte.

Bötkers läge mitt emellan Estland och Sverige är intressant. Han tillbringade sin barndom i Estland men har sedan dess bott i Sverige, och därför är han inte riktigt inne i Estland, men inte heller riktigt utanför. Han har en annan position än de forskare har som ser situationen inifrån - han tycks vara enastående fri att se med djupt kritisk blick på utvecklingen - men också än de vars estniska bakgrund är mer avlägsen, till exempel andra generationens invandrare som är utbildade i USA. Bötkers speciella ställning framträder på ett tankeväckande sätt i hans okonventionella, ibland ikonoklastiska, tänkande, som må vara kontroversiellt men också belyser författarens obundenhet och hans förmåga att föra in ett nytt synsätt i analysen av estnisk politik. 


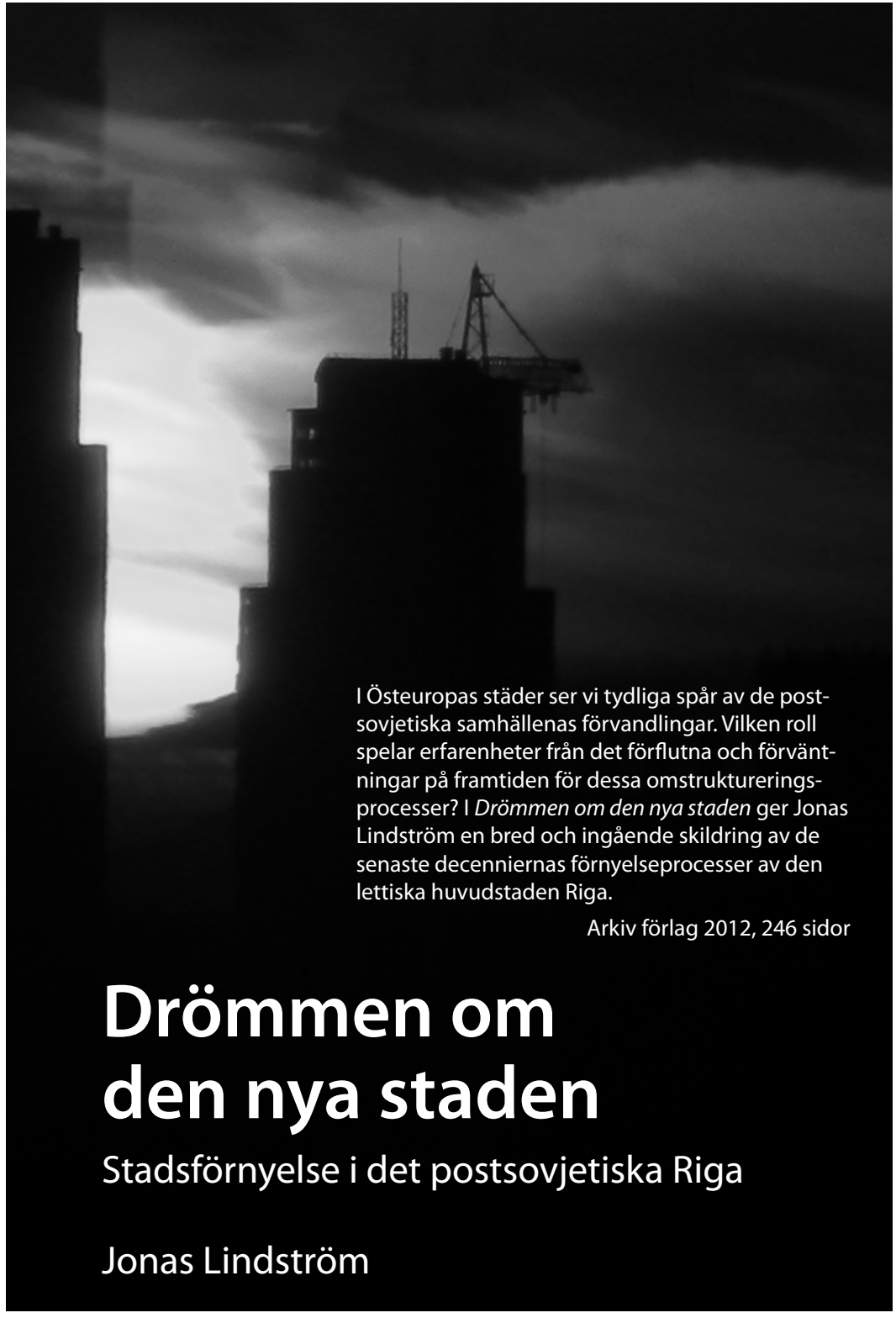

»Läs mer om boken på www.arkiv.nu« 


\section{ATT STUDERA}

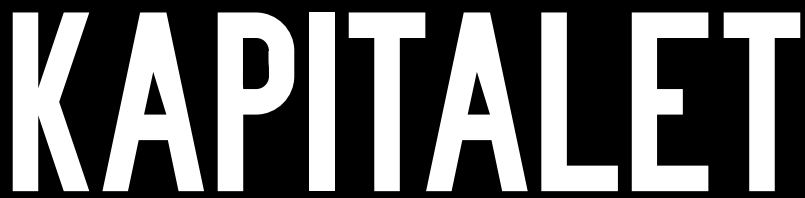

FÖRSTA BOKEN

\section{MATS LINDBERG}

I Att studera Kapitalet tar Mats Lindberg (tidigare Dahlkvist) fasta på Kapitalet betraktad som samhällsvetenskaplig teori: Vad handlar teorin om? Hur är teorin uppbyggd? Hur förhåller den sig till allmän historieteori, empirisk samhällsforskning och praktisk politik? Boken är uppbyggd som en textkommentar och studiehandledning som tar läsaren genom Kapitalets första bok sida för sida, kapitel för kapitel.

Arkivs nya utgåva är ett nytryck av denna inflytelserika doktorsavhandling från 1978. Hur författaren i dag ser på Kapitalets teori framgår av hans inledning till Arkivs sjätte upplaga av Kapitalets första bok 20I3. Den nyskrivna inledningen kan därmed också ses som ett kommenterande förord till detta nytryck, och ett förtydligande ställningstagande till Marx av i dag.

Ny utgåva, Arkiv förlag 2013, 665 sidor 